\title{
Editorial - Volume 10, 2016
}

This is the tenth Volume of the OUSL Journal, the Journal of the Open University of Sri Lanka. The articles published in this volume include research based on floriculture, agriculture, education and social sciences by academics in a number of universities in Sri Lanka and Nigeria. This year we have received an excellent response from our readers and thirty full papers covering many subject areas have been submitted from researchers in Sri Lanka, Nigeria and India. We hope to publish our Journal biannually thus; other articles will be published in the Volume 11.

At present, due to various reasons, both parents are forced to work full time or part time to meet the obligations of their family lives. Apart from day-to-day house work of cooking, cleaning, shopping, and bringing up of their children, female academics engage in teaching, setting questions, marking answer scripts, research, supervising undergraduate/postgraduate students and carrying out administrative work. The first research paper by Oludeyi and Olajide titled "Occupational wellbeing among female academics; the influence of family-work interface" examines the influence of workfamily interface on occupational and general wellbeing of women in academia. Research findings suggest that work-family interface significantly correlates with, and influences both occupational and general wellbeing of female academics. It also suggests that efforts should be geared towards formulating a policy to balance workfamily interface for women academics considering job sharing, compressed working hours, self-rostering, telecommuting, flexi-time, child-care assistance, and so forth.

Floriculture is a profitable industry in Sri Lanka having about $25 \%$ of the annual export earnings. Dendrobium orchid has a good demand in the export and local market due to its vivid and variable flower colouration. Weerahewa, in her research article, focuses on improving floricultural quality, growth and enhancing disease resistance of Dendrobium by preharvest application of soluble silicon. All $100 \mathrm{mg} / \mathrm{L}$ silicon treated plants either weekly or bi-weekly showed a higher shoot length, higher leaf length and number of leaves compared to controls. Plants grown in newly 
developed aeroponics system and treated with $50 \mathrm{mg} / \mathrm{L}$ silicon weekly showed better floricultural quality traits such as a higher number of flowers per spike and greater spike length, while the $100 \mathrm{mg} / \mathrm{L}$ treatment showed greater spike thickness and greater flower length and diameter. Natural disease development was significantly lower in plants treated with silicon. Average leaf thickness and cuticle thickness were significantly higher in plants treated with silicon as was the total soluble phenol content.

Godawatta and De Silva, in their article, discuss the impact of different mulches on growth and yield of Red Okra (abelmoschus esculentus). This study showed that Red Okra plants exposed to temperature stress gave a harvest $37 \%$ higher than the pods grown under ambient temperature. As straw is freely available in the dry zone in Sri Lanka, farmers can use straw mulch successfully when the temperature stress is a limiting factor for higher productivity.

There are many parameters such as adsorption ability, catalytic activity, sensitivity and thermodynamic stability of materials that are important for gas sensing. Bandara et al., in their paper titled "Effects of surface modification of $\mathrm{n}-\mathrm{Cu}_{2} \mathrm{O} / \mathrm{p}-\mathrm{Cu}_{\mathrm{x}} \mathrm{S}$ thin film heterostructures for enhanced liquefied petroleum (LP) gas sensing properties", report a novel mechanism to effectively detect LP gas based on surface modification through sulphidation followed by passivation of electrodeposited $n$-type cuprous oxide $\left(\mathrm{Cu}_{2} \mathrm{O}\right)$. It was found that the sensitivity of LP gas detection can be improved by $48 \%$ at a relatively low sensing temperature of $45{ }^{\circ} \mathrm{C}$. Thus, the sulphidation has caused LP gas molecules to interact with the film surface more actively with a 10 fold increase when compared to the maximum sensitivity of untreated $\mathrm{Cu}_{2} \mathrm{O}$ films at $85^{\circ} \mathrm{C}$.

Sri Lanka has become the world's third largest tea exporter in the world. Sri Lankan Tea is famous for its signature taste and aroma. Kavish et al., in their paper titled "Impact of inlet drying temperature in Endless Chain Pressure (ECP) dryers on the quality characteristics of leafy type of tea produced using different leaf standards", investigate the appropriate higher inlet drying temperatures in ECP dryers to assess the improvement of quality 
characteristic of tea of seven grades (OP, OP1, PEKOE, FBOPF, FBOP, FBOPF1 and OPA). Results revealed that there was no significant difference in liquoring properties of made tea produced at higher drying inlet temperature $\left(230{ }^{\circ} \mathrm{F}\right)$ when compared to $205^{\circ} \mathrm{F}$ for the three different leaf standards of $40 \%, 50 \%$ and $60 \%$ of good leaves tested.

Human smuggling affects at least three countries such as the country of origin, transits, and destination. It has an impact on the international relations, security and economy of these countries. Kathirgamthamby, in her paper titled "Human smugglingimplications on rights of migrants: an examination from the standpoint of International Law", seeks to inquire into and examine the rights of smuggled migrants particularly giving special attention to United Nations Convention against Transnational Organized Crime 2000 (UNCTOC) and the Protocol against the smuggling of migrants by land, sea and land supplementing the United National Convention against Transnational Organized Crimes 2000 (Protocol). This study shows that the smuggling protocol focuses more on punishing the offenders rather than protecting the rights of smuggled migrants. Although UNCTOC and the smuggling protocol aim to protect the rights of smuggled migrants, the convention does not impose any legal obligation and the countries are free to take actions as they please.

This volume also includes the Convocation Address-2016 made by Prof. Asha Singh Kanwar, President and Chief Executive Officer of the Commonwealth of Learning. She emphasizes five forces, namely (i) the force of technology, (ii) the force of globalization, (iii) the force of demography and longevity, (iv) the force of society, and (v) the force of energy resources, which may change how we work in the future.

We welcome your suggestions for further improvement of this journal. We look forward to publishing your cur findings in our next volume.

Professor K. Sarath D. Perera

Editor in Chief/OUSL Journal 